\title{
Differences in medical specialist utilization among older people in need of long-term care - results from German health claims data
}

Maike Schulz ${ }^{1,5^{*}}$ D, Jonas Czwikla ${ }^{1,5}$, Chrysanthi Tsiasioti ${ }^{3}$, Antje Schwinger ${ }^{3}$, Daniel Gand ${ }^{2,5}$, Guido Schmiemann ${ }^{2,5}$, Annika Schmidt ${ }^{2,5}$, Karin Wolf-Ostermann ${ }^{2,5}$, Stephan Kloep ${ }^{4,5}$, Franziska Heinze ${ }^{1,5}$ and Heinz Rothgang ${ }^{1,5}$

\begin{abstract}
Background: Elderly in need of long-term care tend to have worse health and have higher need of medical care than elderly without need for long-term care. Yet, characteristics associated with long-term care need can impede health care access: Higher levels of long-term care need come with physical and cognitive decline such as frailty and memory loss. Yet, it has not been investigated whether level of long-term care need is related to medical care utilization.

Methods: We investigated the association between the level of long-term care and medical specialist utilization among nursing home residents and home care recipients. We applied zero-inflated Poisson regression with robust standard errors based on a sample of statutory health insurance members. The sample consisted of 100.000 elderly over age 60 . We controlled for age, gender, morbidity and mortality, residential density, and general practitioner utilization.

Results: We found a strong gradient effect of the level of long-term care for 9 out of 12 medical specialties: A higher level of long-term care need was associated with a lower probability of having a medical specialist visit. Yet, we did not find clear effects of the level of long-term care need on the intensity of medical specialist care. These findings were similar for both the nursing home and home care setting.

Conclusion: The findings indicate that inequalities in medical specialist utilization exist between elderly with differing levels of long-term care need because differences in morbidity were controlled for. Elderly with higher need of longterm care might face more access barriers to specialist medical care.
\end{abstract}

Keywords: Elderly, Medical care, Claims data, Nursing homes, Nursing home residents

\section{Background}

Higher age is associated with increasing morbidity and higher health care utilization [1]. In industrialized countries, the majority of the elderly aged 60 years and over suffer from at least one chronic disease [2-4]. Consequently, elderly people show higher health care need and

\footnotetext{
*Correspondence: maike.schulz@uni-bremen.de

${ }^{1}$ University of Bremen, SOCIUM Research Center on Inequality and Social

Policy, Mary-Somerville-Straße 5, 28359 Bremen, Germany

${ }^{5}$ University of Bremen, High-Profile Area Health Sciences, Bremen, Germany

Full list of author information is available at the end of the article
}

higher utilization of medical care than the overall population $[5,6]$.

However, previous studies have shown that those elderly who have need for long-term care tend to have unmet health care needs. For instance, elderly who live in nursing homes have less visits to medical specialists such as dentists, orthopedists, ophthalmologists and otorhinolaryngologist [7-12]. Consequently, if this lower level of medical utilization represents unmet care needs nursing home residents may be at risk of adverse outcomes, i.e. inadequate medication and therapy, avoidable hospitalizations, or falls [13-18]. 
The reasons for lower health care utilization of elderly in need of long-term care may lie in their physical and mental limitations. Frailty is an increasing phenomenon in the elderly population [19], and elderly in need of long-term care tend to be more frail than those without need of long-term care [20]. As a consequence, elderly in need of long-term care need more support in activities of daily living [21]. Moreover, elderly people in need of long-term care often suffer from cognitive impairment such as dementia [22-24]. Both frailty and cognitive impairment can increase the risk of unmet health care needs and perceive barriers to health care because the elderly may have more difficulties to assess their health care need, and to organize health care [25-28].

In Germany, about $90 \%$ of the population (i.e. 73 million people) are members of the statutory health insurance and therefore automatically also members of the statutory long-term care insurance. Only $10 \%$ of the population uses private health insurance and private long-term care insurance. Insured persons with physical and mental limitations can obtain long-term care benefits either in cash (to organize informal care by informal caregivers at their home), or in kind (to organize formal care at their home or long-term care in nursing homes). People with higher levels of long-term care obtain higher benefits from the long-term care insurance than people with lower levels of long-term care need. Benefits are granted irregardless of personal or household income or assets. However, benefits are capped, and statutorily insured persons have to pay the remainder if the costs of long-term care services exceed the granted benefits. The goal of these benefits is to provide insured persons with physical and mental limitations with support in activities of daily living. Therefore, long-term care services are distinct from medical services which aim to cure or prevent diseases.

Depending on the degree of physical and mental limitations and the according need for assistance in matters of daily life, care-dependent people are assigned a level of long-term care need. In Germany, until 2016, the level of long-term care need was called Pflegestufe. The Pflegestufe differentiated between the levels 1,2, 3, and hardship cases. People in level 1 need assistance with daily activities (i.e. personal hygiene, mobility or eating) once a day, whereas people in level 2 need assistance three times a day. People in level 3 need several hours of assistance over the whole day. Hardship cases need at least $7 \mathrm{~h}$ of assistance during the day and at least $2 \mathrm{~h}$ of assistance during the night. In 2017, the Pflegestufe was replaced by the Pflegegrad which now differentiates between five care grades.

As elderly with a higher level of long-term care need are more limited in matters of daily life including the organization of medical care, they may have a higher risk of inadequate health care. However, although health care utilization of older people has been investigated [5, 29, 30], existing research on health care utilization of older people in need of long-term care is limited [31].

Consequently, the aim of this study is to focus on this particular group and to investigate whether differences in the utilization of 12 medical specialties exist between elderly in need of long-term care and elderly who are not in need of long-term care with a special focus on both the level of long-term care and the care setting. Such differences could indicate perceived access barriers and inequalities in medical care utilization among caredependent elderly. In the following sections we describe our data source and statistical analysis followed by a description of our descriptive and multivariate findings. The findings are then discussed in the discussion section. Finally a conclusion is drawn.

\section{Methods}

\section{Data source}

We used claims data from the German health and longterm care insurance AOK (Allgemeine Ortskrankenkasse). The AOK consists of eleven regional health insurance funds which, taken together, represent the largest statutory health insurance fund in Germany. More than a third of the population who has statutory health insurance is covered by the AOK.

We drew a sample of 100,000 insured persons aged 60 years and over from the total AOK population. About $15 \%$ of the insured persons in this sample were in need of long-term care. This way, the sample represents the percentage of older people in need of long-term care among the total AOK population aged 60 years and over in Germany. Of these older people in need of long-term care, 5100 were nursing home residents and 9700 were community-dwelling elderly who received formal or informal home care. The insurance data included medical care visits, inpatient and outpatient diagnoses based on the German Modification of the International Classification of Diseases, 10th Revision, (ICD-10-GM), and sociodemographic characteristics (i.e. age, gender, and type of residential location).

\section{Statistical analysis}

We applied zero-inflated Poisson regression with robust standard errors to model the distribution of medical care utilization. Zero-inflated Poisson regression accounts for non-normal distributions where there are many zero values. Although older people show high mean levels of health care utilization, there is considerable variation between non-morbid and multimorbid older people [5]. For instance, healthy elderly are more likely to have no medical care visits, and such zero-inflation is more likely 
to occur in medical specialist utilization or hospital utilization than in general practitioner utilization [32]. The zero-inflated Poisson model contains two components; the first part of the model predicts nonoccurrence of a behavior, in our case the probability of not having any medical specialist visit. The second part of the model estimates how frequently the behavior occurred, i.e. the intensity of medical specialist care [33]. Yet, for two models (internist and orthopedics utilization among elderly with diagnosed motor impairment) a logistic regression was calculated because it fit the distribution of the data better than a zero-inflated Poisson.

The dependent variable was the overall visits to medical specialists in 2015. However, health insurance claims data do not reflect the actual number of visits but only those visits that were charged by physicians and were remunerated by statutory health insurance funds. Consequently, claims data document repeated visits to the same physician only once per quarter. However, if different physicians were contacted per quarter each visit was captured. We investigated 12 medical specialties. For each specialty, we included only those in a disease category that was relevant for the respective medical specialty under study. Multiple models were calculated per specialty when more than one diagnosis was relevant. Table 2 shows the resulting 45 models.

The main independent variable was combined from the level of long-term care (Pflegestufe) and the longterm care setting (nursing home vs. home care). We grouped the Pflegestufe into 3 levels of long-term care need $($ low $=$ Pflegestufe 1 , medium $=$ Pflegestufe 2 , and high $=$ Pflegestufe 3 and hardship cases) and generated dummy variables for each of the 3 levels of long-term care need. Both long-term care settings were also defined as dummy variables and combined with the longterm care need. This resulted in 6 dummy variables differentiating between nursing home residents with low/ medium/high long-term care need, and home care recipients with low/medium/high long-term care need. The reference group was older people without need of longterm care. These 6 dummy variables were included in all models; however, although both settings were included in the models simultaneously, we present each setting in a separate results table to fit on one page. Additional file 2 includes both settings.

We defined "older people in need of long-term care" as all people who are in need of long-term care according to $\$ 14$, German Social Code XI and who were assessed according to $₫ 18$, German Social Code XI. This means that the need of long-term care was legally assessed by the Medical Advisory Service of the German statutory health insurance funds ("Medizinischer Dienst der Krankenversicherung"). The assessment is based on nationwide guidelines and is conducted by trained nurses or physicians who observe and interview the persons in need of long-term care and relatives.

Control variables were age in 2015 (categorized into 7 groups), gender, mortality in 2015, overall visits to general practitioners in 2015, type of residential location (i. e. city, urban, and rural), and morbidity. We defined morbidity of each elderly based on diagnoses from the years 2014 and 2015 and categorized into 31 disease categories based on ICD-10 GM.

We investigated the stability of the findings by excluding the long-term care setting from the models; these models include only the covariates for long-term care need and are shown in Additional file 3. The results did not differ considerably from those presented in the results section.

\section{Results}

\section{Descriptive findings}

Table 1 shows that the elderly visit medical specialists on average between 0.3 and 2.1 times per year depending on the disease group and the type of medical specialty. The standard deviation of mostly 1.5 to 2.0 indicates that most elderly have between 0 and 4 annual visits to medical specialists. However, utilization ranges from 0 up until 35 visits. Further descriptive statistics on the characteristics of the sample are shown in Additional file 1.

The bivariate results in Table 2 indicate that there are clear differences in medical specialist utilization between elderly with and without need of long-term care. For instance, we find that among the elderly with a renal failure diagnosis, $57 \%$ of those with a low level of long-term care need did not have a visit to a physician of internal medicine. Among the elderly with a medium or high level of long-term care need 67 and 79\%, respectively, did not have such a visit. In contrast, among the elderly with a renal failure diagnosis but without need of long-term care, only $44 \%$ did not have a visit to a physician of internal medicine. These patterns persist for all medical specialties except for urology and psychiatry/neurology; utilization of urologists is similar among elderly of all levels of longterm care. The probability of visiting neurologists or psychiatrists given a respective disease is higher among elderly with higher levels of long-term care.

\section{Multivariate findings}

First, we found significant strong gradient effects of the level of long-term care on the probability of having no specialist visit for 8 out of 12 medical specialties, i.e. internal medicine, cardiology, ophthalmology, orthopedics, gynecology, nephrology, pneumology, psychiatry/neurology (Table 3 and Additional file 2: Table S2). In most of these cases (except for psychiatry/neurology), this means that higher levels of longterm care need were associated with a lower probability of having a medical specialist visit compared to the reference 
Table 1 Descriptive statistics on specialist utilization among the elderly given a respective disease

\begin{tabular}{|c|c|c|c|c|c|c|}
\hline \multirow[t]{2}{*}{ Medical specialty } & \multirow[t]{2}{*}{ Disease category } & \multicolumn{5}{|c|}{ Annual medical specialist utilization } \\
\hline & & Sample size & Mean visits & Minimum & Maximum & Standard deviation \\
\hline \multirow[t]{16}{*}{ Internal medicine } & Renal failure & 12,340 & 1.65 & 0 & 35 & 2.57 \\
\hline & Respiratory disease & 18,303 & 1.56 & 0 & 32 & 2.21 \\
\hline & Heart disease & 40,632 & 1.34 & 0 & 35 & 2.06 \\
\hline & Mono- and polyneuropathy & 13,426 & 1.34 & 0 & 31 & 2.16 \\
\hline & Nutrition-related disease & 17,016 & 1.28 & 0 & 31 & 2.07 \\
\hline & Cerebrovascular disease & 14,389 & 1.25 & 0 & 31 & 2.05 \\
\hline & Coronary disease & 32,416 & 1.21 & 0 & 32 & 2.00 \\
\hline & Intestinal disease & 32,557 & 1.21 & 0 & 35 & 1.99 \\
\hline & Metabolic disorders & 48,913 & 1.11 & 0 & 35 & 1.91 \\
\hline & Diabetes mellitus & 30,683 & 1.11 & 0 & 32 & 1.96 \\
\hline & Thyroid disorders & 23,589 & 1.11 & 0 & 35 & 1.92 \\
\hline & Parkinson's disease & 4887 & 1.10 & 0 & 30 & 2.01 \\
\hline & Arthropathy & 43,937 & 1.06 & 0 & 35 & 1.87 \\
\hline & Hypertension & 69,439 & 1.01 & 0 & 35 & 1.83 \\
\hline & Motor impairment & 2533 & 0.83 & 0 & 14 & 1.57 \\
\hline & Palsy/paresis & 2734 & 0.73 & 0 & 28 & 1.68 \\
\hline \multirow[t]{3}{*}{ Cardiology } & Heart disease & 40,632 & 0.50 & 0 & 12 & 0.97 \\
\hline & Coronary disease & 32,416 & 0.35 & 0 & 12 & 0.85 \\
\hline & Hypertension & 69,439 & 0.31 & 0 & 12 & 0.78 \\
\hline Ophthalmology & Diseases of the eye & 33,333 & 2.06 & 0 & 12 & 1.57 \\
\hline \multirow[t]{5}{*}{ Orthopedy } & Osteopathy and chondropathy & 14,807 & 1.05 & 0 & 10 & 1.52 \\
\hline & Arthropathy & 43,937 & 0.89 & 0 & 12 & 1.39 \\
\hline & Injury & 13,313 & 0.89 & 0 & 10 & 1.42 \\
\hline & Spinal disease & 46,093 & 0.87 & 0 & 12 & 1.37 \\
\hline & Motor impairment & 2533 & 0.52 & 0 & 7 & 1.13 \\
\hline \multirow[t]{2}{*}{ Gynecology } & Disorders of female genital tract & 9041 & 2.08 & 0 & 15 & 1.83 \\
\hline & Urinary tract disease & 19,362 & 0.52 & 0 & 13 & 1.22 \\
\hline \multirow[t]{2}{*}{ Urology } & Prostate disease & 11,666 & 1.80 & 0 & 16 & 1.72 \\
\hline & Urinary tract disease & 19,362 & 1.11 & 0 & 11 & 1.63 \\
\hline \multirow[t]{2}{*}{ Surgery } & Injury & 13,313 & 0.36 & 0 & 10 & 0.86 \\
\hline & Skin disease & 12,848 & 0.26 & 0 & 10 & 0.74 \\
\hline \multirow[t]{2}{*}{ Dermatology } & Skin disease & 12,848 & 1.26 & 0 & 9 & 1.50 \\
\hline & Bedsore/decubitus & 6618 & 0.99 & 0 & 9 & 1.42 \\
\hline Otolaryngology & Diseases of the ear & 18,325 & 1.27 & 0 & 10 & 1.33 \\
\hline Nephrology & Renal failure & 12,340 & 0.53 & 0 & 31 & 1.58 \\
\hline Pneumology & Respiratory disease & 18,303 & 0.57 & 0 & 9 & 1.17 \\
\hline \multirow[t]{9}{*}{ Psychiatry / Neurology } & Parkinson's disease & 4887 & 1.67 & 0 & 11 & 1.87 \\
\hline & Delusional/personality disorders & 2925 & 1.65 & 0 & 10 & 1.92 \\
\hline & Dementia-related disease & 10,807 & 1.22 & 0 & 10 & 1.72 \\
\hline & Palsy/paresis & 2734 & 1.21 & 0 & 9 & 1.75 \\
\hline & Depression & 18,477 & 0.99 & 0 & 11 & 1.60 \\
\hline & Neurosis & 13,426 & 0.77 & 0 & 9 & 1.39 \\
\hline & Mono- and polyneuropathy & 13,426 & 0.77 & 0 & 9 & 1.39 \\
\hline & Cerebrovascular disease & 14,389 & 0.75 & 0 & 9 & 1.42 \\
\hline & Disorders due to psychoactive substance use & 7162 & 0.58 & 0 & 9 & 1.31 \\
\hline
\end{tabular}


Table 2 Descriptive statistics: Share of elderly with no medical specialist visit in 2015 by level of long-term care

\begin{tabular}{|c|c|c|c|c|c|c|c|c|c|}
\hline \multirow[t]{3}{*}{ Medical specialty } & \multirow[t]{3}{*}{ Disease categories } & \multicolumn{6}{|c|}{ Elderly in need of long-term care } & \multirow{2}{*}{\multicolumn{2}{|c|}{$\begin{array}{l}\text { Elderly not in } \\
\text { need of long- } \\
\text { term care }\end{array}$}} \\
\hline & & \multicolumn{2}{|c|}{ Low level of care } & \multicolumn{2}{|c|}{ Medium level of care } & \multicolumn{2}{|c|}{ High level of care } & & \\
\hline & & Share & $n$ & Share & $\mathrm{n}$ & $\%$ & $n$ & Share & $n$ \\
\hline \multirow[t]{16}{*}{ Internal medicine } & Renal failure & $57 \%$ & 2040 & $67 \%$ & 1483 & $79 \%$ & 518 & $44 \%$ & 8299 \\
\hline & Respiratory disease & $56 \%$ & 1929 & $68 \%$ & 1236 & $78 \%$ & 401 & $46 \%$ & 14,737 \\
\hline & Heart disease & $62 \%$ & 4941 & $72 \%$ & 3222 & $83 \%$ & 1270 & $46 \%$ & 31,199 \\
\hline & Mono- and polyneuropathy & $59 \%$ & 1709 & $67 \%$ & 1044 & $75 \%$ & 315 & $52 \%$ & 10,358 \\
\hline & Nutrition-related disease & $59 \%$ & 1596 & $67 \%$ & 907 & $77 \%$ & 274 & $54 \%$ & 14,239 \\
\hline & Cerebrovascular disease & $67 \%$ & 2106 & $76 \%$ & 1790 & $84 \%$ & 822 & $47 \%$ & 9671 \\
\hline & Coronary disease & $63 \%$ & 3632 & $72 \%$ & 2244 & $81 \%$ & 843 & $54 \%$ & 25,697 \\
\hline & Intestinal disease & $63 \%$ & 3057 & $74 \%$ & 2118 & $86 \%$ & 882 & $52 \%$ & 26,500 \\
\hline & Metabolic disorders & $63 \%$ & 4110 & $72 \%$ & 2670 & $83 \%$ & 1059 & $57 \%$ & 41,074 \\
\hline & Diabetes mellitus & $64 \%$ & 3338 & $73 \%$ & 2260 & $82 \%$ & 871 & $57 \%$ & 24,214 \\
\hline & Thyroid disorders & $62 \%$ & 1983 & $73 \%$ & 1153 & $85 \%$ & 444 & $57 \%$ & 20,009 \\
\hline & Parkinson's disease & $65 \%$ & 743 & $74 \%$ & 674 & $86 \%$ & 383 & $54 \%$ & 3087 \\
\hline & Arthropathy & $65 \%$ & 4184 & $74 \%$ & 2505 & $83 \%$ & 876 & $58 \%$ & 36,372 \\
\hline & Hypertension & $67 \%$ & 6363 & $75 \%$ & 4054 & $85 \%$ & 1646 & $60 \%$ & 57,376 \\
\hline & Motor impairment & $76 \%$ & 505 & $80 \%$ & 402 & $88 \%$ & 153 & $58 \%$ & 1473 \\
\hline & Palsy/paresis & $72 \%$ & 575 & $80 \%$ & 777 & $89 \%$ & 393 & $61 \%$ & 989 \\
\hline \multirow[t]{3}{*}{ Cardiology } & Heart disease & $81 \%$ & 4941 & $88 \%$ & 3222 & $95 \%$ & 1270 & $68 \%$ & 31,199 \\
\hline & Coronary disease & $83 \%$ & 3632 & $89 \%$ & 2244 & $96 \%$ & 843 & $78 \%$ & 25,697 \\
\hline & Hypertension & $85 \%$ & 6363 & $90 \%$ & 4054 & $96 \%$ & 1646 & $81 \%$ & 57,376 \\
\hline Ophthalmology & Diseases of the eye & $2 \%$ & 3100 & $43 \%$ & 1685 & $60 \%$ & 591 & $16 \%$ & 27,957 \\
\hline \multirow[t]{5}{*}{ Orthopedics } & Osteopathy and chondropathy & $66 \%$ & 2034 & $80 \%$ & 1194 & $86 \%$ & 466 & $53 \%$ & 11,113 \\
\hline & Arthropathy & $71 \%$ & 4184 & $82 \%$ & 2505 & $87 \%$ & 876 & $58 \%$ & 36,372 \\
\hline & Injury & $70 \%$ & 2017 & $83 \%$ & 1629 & $89 \%$ & 653 & $54 \%$ & 9014 \\
\hline & Spinal disease & $68 \%$ & 3792 & $80 \%$ & 2058 & $86 \%$ & 721 & $59 \%$ & 39,522 \\
\hline & Motor impairment & $81 \%$ & 505 & $89 \%$ & 402 & $92 \%$ & 153 & $70 \%$ & 1473 \\
\hline \multirow[t]{2}{*}{ Gynecology } & Disorders of female genital tract & $22 \%$ & 1014 & $28 \%$ & 456 & $32 \%$ & 158 & $13 \%$ & 16,454 \\
\hline & Urinary tract disease & $88 \%$ & 2861 & $94 \%$ & 2830 & $96 \%$ & 1408 & $72 \%$ & 12,263 \\
\hline \multirow[t]{2}{*}{ Urology } & Prostate disease & $21 \%$ & 1564 & $20 \%$ & 1228 & $21 \%$ & 420 & $17 \%$ & 20,120 \\
\hline & Urinary tract disease & $74 \%$ & 2861 & $73 \%$ & 2830 & $78 \%$ & 1408 & $51 \%$ & 12,263 \\
\hline \multirow[t]{2}{*}{ Surgery } & Injury & $83 \%$ & 2017 & $86 \%$ & 1629 & $90 \%$ & 653 & $77 \%$ & 9014 \\
\hline & Skin disease & $85 \%$ & 1244 & $88 \%$ & 898 & $88 \%$ & 898 & $84 \%$ & 10,330 \\
\hline \multirow[t]{2}{*}{ Dermatology } & Skin disease & $54 \%$ & 1244 & $58 \%$ & 898 & $57 \%$ & 376 & $46 \%$ & 10,330 \\
\hline & Bedsore/decubitus & $68 \%$ & 805 & $75 \%$ & 849 & $83 \%$ & 555 & $49 \%$ & 4409 \\
\hline Otolaryngology & Diseases of the ear & $47 \%$ & 1853 & $50 \%$ & 1056 & $59 \%$ & 446 & $38 \%$ & 14,970 \\
\hline Nephrology & Renal failure & $83 \%$ & 2040 & $88 \%$ & 1483 & $92 \%$ & 518 & $81 \%$ & 8299 \\
\hline Pneumology & Respiratory disease & $81 \%$ & 1929 & $88 \%$ & 1236 & $93 \%$ & 401 & $73 \%$ & 14,737 \\
\hline \multirow[t]{6}{*}{ Psychiatry/ Neurology } & Parkinson's disease & $45 \%$ & 743 & $43 \%$ & 674 & $39 \%$ & 383 & $50 \%$ & 3087 \\
\hline & Delusional/personality disorders & $48 \%$ & 464 & $43 \%$ & 363 & $38 \%$ & 233 & $54 \%$ & 1865 \\
\hline & Dementia-related disease & $60 \%$ & 2470 & $54 \%$ & 2538 & $53 \%$ & 1504 & $66 \%$ & 4295 \\
\hline & Palsy/paresis & $62 \%$ & 575 & $57 \%$ & 777 & $52 \%$ & 393 & $66 \%$ & 989 \\
\hline & Depression & $62 \%$ & 2236 & $55 \%$ & 1543 & $51 \%$ & 681 & $69 \%$ & 14,017 \\
\hline & Neurosis & $64 \%$ & 1553 & $57 \%$ & 886 & $52 \%$ & 306 & $72 \%$ & 14,167 \\
\hline
\end{tabular}


Table 2 Descriptive statistics: Share of elderly with no medical specialist visit in 2015 by level of long-term care (Continued)

\begin{tabular}{|c|c|c|c|c|c|c|c|c|c|}
\hline \multirow[t]{3}{*}{ Medical specialty } & \multirow[t]{3}{*}{ Disease categories } & \multicolumn{6}{|c|}{ Elderly in need of long-term care } & \multirow{2}{*}{\multicolumn{2}{|c|}{$\begin{array}{l}\text { Elderly not in } \\
\text { need of long- } \\
\text { term care }\end{array}$}} \\
\hline & & \multicolumn{2}{|c|}{ Low level of care } & \multicolumn{2}{|c|}{ Medium level of care } & \multicolumn{2}{|c|}{ High level of care } & & \\
\hline & & Share & $\mathrm{n}$ & Share & $\mathrm{n}$ & $\%$ & $\mathrm{n}$ & Share & $\mathrm{n}$ \\
\hline & Mono- and polyneuropathy & $67 \%$ & 1709 & $63 \%$ & 1044 & $57 \%$ & 315 & $71 \%$ & 10,358 \\
\hline & Cerebrovascular disease & $69 \%$ & 2106 & $61 \%$ & 1790 & $58 \%$ & 822 & $76 \%$ & 9671 \\
\hline & Disorders due to psychoactive substance use & $67 \%$ & 685 & $64 \%$ & 388 & $47 \%$ & 135 & $82 \%$ & 5954 \\
\hline
\end{tabular}

Notes: Sample size $n=100,000$ insured persons of the AOK health and long-term care insurance fund

Low level = i.e. German „Pflegestufe 1", medium level = „Pflegestufe 2", high level = „Pflegestufe 3 "and hardship cases, disease categories are related to ICD-10-GM

group without need of long-term care. For urology, surgery, dermatology, and otolaryngology, we cannot confirm a gradient effect because the majority of the effects was not significant. The largest gradient effects were found for the specialties cardiology, ophthalmology, and internal medicine given the respective disease (Table 3 and Additional file 2: Table S2).

For instance, nursing home residents with a low longterm care level who have any of the investigated eye diseases have a $243 \%$ increase in risk of having no ophthalmology visit compared to the reference group, i.e. elderly with no need of long-term care. Nursing home residents with the highest long-term care level have a $575 \%$ increase in risk of seeing no ophthalmologist. The gradient effect is even larger in in the home care setting (Table 4): home care recipients with a low level of longterm care have a $136 \%$ increase in risk of having no ophthalmologist visit whereas those with the highest longterm care level have a $914 \%$ increase in risk compared to the reference group.

For internal medicine, we found significant effects for all 16 investigated disease groups. However, for a few of these disease groups in certain settings, we could not confirm a consistent gradient effect with increasing levels of received long-term care (i. e. mono- and polyneuropathy, motor impairment and Parkinson's disease among nursing home residents). For gynaecology, urology, and orthopedics we also found gradient effects but not for all of the investigated disease groups.

A reversed gradient effect was found for utilization of psychiatry/neurology: nursing home residents showed a lower probability of having no specialist visit than elderly without need of long-term care. There were hardly any effects of the level of long-term care on utilization of surgery: We found no significant effects among home care recipients, and no consistent effects among nursing home residents.

In all of these models, we controlled for General Practitioner (GP) utilization. There were however no or only small significant associations with medical specialist utilization. For some medical specialties, GP utilization was associated with a lower probability of having no specialist visit. This indicated no systematic substitution effects between GPs and medical specialists (see Additional file 4).

Second, for most medical specialties, we found no consistent gradient effect of the level of long-term care on the number of specialist visits (i.e. the intensity of specialist care) (Additional file 2: Table S2). Only in the case of neurologist/psychiatrist utilization, nursing home residents with higher levels of long-term care need tended to receive a higher intensity of medical care than those nursing home residents with lower levels of long-term care need.

Third, the effects of the level of long-term care were similar in both the home care and nursing home setting (Additional file 2: Table S2). We only found clear differences between the settings for the medical specialties dermatology, otolaryngology, and neurology/ psychiatry. For dermatology, there were only small effects for nursing home residents but strong gradient effects for home care recipients. For otolaryngology, it was vice versa: we found no significant effects for home care recipients but strong gradient effects for nursing home residents. For neurology/psychiatry, nursing home residents showed a lower risk of having no specialist visit whereas the effects of the home care setting were rather inconsistent.

\section{Discussion}

We gave an overview of medical specialist utilization of elderly people with differing levels of long-term care need. When controlling for differences in morbidity, we found that elderly with higher levels of long-term care were at a much higher risk of having no medical specialist visit than elderly who were not in need of long-term care. This finding applies to 8 out of 12 medical specialties, and the results were similar among the home care and the nursing home setting.

These findings support the importance of differentiating medical care utilization between elderly with and without need of long-term care. Although our descriptive findings showed that older people have on average at least one annual utilization to medical specialists, the picture is more nuanced. Our findings support previous studies that have already shown that elderly in need for 
Table 3 Nursing home residents: LTC need level and the risk of having no medical specialist visit

\begin{tabular}{|c|c|c|c|c|c|}
\hline \multirow{2}{*}{$\begin{array}{l}\text { Medical } \\
\text { specialty }\end{array}$} & \multirow[b]{2}{*}{ Disease categories } & \multicolumn{4}{|c|}{ Long-term care setting: Nursing home } \\
\hline & & $\begin{array}{l}\text { Low } \\
\text { level }\end{array}$ & \begin{tabular}{|c|}
$\begin{array}{c}\text { Medium } \\
\text { level }\end{array}$ \\
\end{tabular} & $\begin{array}{l}\text { High } \\
\text { level }\end{array}$ & Visualization \\
\hline \multirow{16}{*}{$\begin{array}{l}\text { Internal } \\
\text { medicine }\end{array}$} & Renal failure & $105 \%$ & $152 \%$ & $249 \%$ & \\
\hline & Respiratory disease & $118 \%$ & $132 \%$ & $296 \%$ & \\
\hline & Heart disease & $109 \%$ & $180 \%$ & $227 \%$ & \\
\hline & Mono- and polyneuropathy & $92 \%$ & $122 \%$ & $91 \%$ & \\
\hline & Nutrition-related disease & $149 \%$ & $169 \%$ & $272 \%$ & \\
\hline & Cerebrovaskular disease & $134 \%$ & $204 \%$ & $377 \%$ & \\
\hline & Coronary disease & $145 \%$ & $176 \%$ & $236 \%$ & \\
\hline & Intestinal disease & $174 \%$ & $209 \%$ & $384 \%$ & \\
\hline & Metabolic disorders & $126 \%$ & $202 \%$ & $263 \%$ & \\
\hline & Diabetes mellitus & $93 \%$ & $142 \%$ & $183 \%$ & 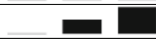 \\
\hline & Thyroid disorders & $96 \%$ & $170 \%$ & $300 \%$ & \\
\hline & Parkinson's disease & $303 \%$ & $116 \%$ & $209 \%$ & \\
\hline & Arthropathy & $131 \%$ & $152 \%$ & $157 \%$ & \\
\hline & Hypertension & $106 \%$ & $156 \%$ & $247 \%$ & \\
\hline & Motor impairment ${ }^{ \pm}$ & $-59 \%$ & $-53 \%$ & $-72 \%$ & \\
\hline & Palsy/paresis & $236 \%$ & $255 \%$ & $332 \%$ & \\
\hline \multirow{3}{*}{ Cardiology } & Heart disease & $116 \%$ & $182 \%$ & $268 \%$ & \\
\hline & Coronary disease & $104 \%$ & $288 \%$ & $477 \%$ & \\
\hline & Hypertension & $114 \%$ & $163 \%$ & $428 \%$ & $=$ \\
\hline Ophthalmology & Diseases of the eye & $243 \%$ & $444 \%$ & $575 \%$ & \\
\hline \multirow{5}{*}{ Orthopedics } & Osteopathy and hondropathy & $64 \%$ & $223 \%$ & $139 \%$ & \\
\hline & Arthropathy & $102 \%$ & $148 \%$ & $157 \%$ & \\
\hline & Injury & $96 \%$ & $192 \%$ & $162 \%$ & \\
\hline & Spinal disease & $74 \%$ & $146 \%$ & $172 \%$ & \\
\hline & Motor impairment ${ }^{\ddagger}$ & $-60 \%$ & $-71 \%$ & $-48 \%$ & \\
\hline \multirow{2}{*}{ Gynecology } & Diseases of the female genital tract & $89 \%$ & $199 \%$ & $75 \%$ & \\
\hline & Urinary tract disease & $179 \%$ & $148 \%$ & $240 \%$ & \\
\hline \multirow{2}{*}{ Urology } & Prostata disease & $38 \%$ & $-4 \%$ & $128 \%$ & \\
\hline & Urinary tract disease & $156 \%$ & $136 \%$ & $91 \%$ & \\
\hline \multirow{2}{*}{ Surgery } & Injury & $-1 \%$ & $4 \%$ & $98 \%$ & \\
\hline & Skin disease & $13 \%$ & $28 \%$ & $123 \%$ & \\
\hline \multirow{2}{*}{ Dermatology } & Skin disease & $-20 \%$ & $-11 \%$ & $-22 \%$ & \\
\hline & Bedsore/decubitus & $58 \%$ & $63 \%$ & $79 \%$ & \\
\hline Otolaryngology & Disease of the ear & $7 \%$ & $-4 \%$ & $33 \%$ & \\
\hline Nephrology & Renal failure & $47 \%$ & $78 \%$ & $138 \%$ & \\
\hline Pneumology & Respiratory disease & $181 \%$ & $157 \%$ & $698 \%$ & \\
\hline \multirow{9}{*}{$\begin{array}{l}\text { Psychiatry / } \\
\text { Neurology }\end{array}$} & Parkinson's diseases & -27 & $-39 \%$ & $-66 \%$ & \\
\hline & Delusional/personality disorders & $-62 \%$ & $-70 \%$ & $-72 \%$ & \\
\hline & Dementia-related disease & $-69 \%$ & $-76 \%$ & $-77 \%$ & \\
\hline & Palsy/paresis & $-52 \%$ & $-59 \%$ & $-73 \%$ & \\
\hline & Depression & $-63 \%$ & $-69 \%$ & $-71 \%$ & \\
\hline & Neurosis & $-60 \%$ & $-70 \%$ & $-76 \%$ & \\
\hline & Mono- and polyneuropathy & $-38 \%$ & $-47 \%$ & $-63 \%$ & \\
\hline & Cerebrovascular disease & $-52 \%$ & $-65 \%$ & $-69 \%$ & \\
\hline & Disorders due to psychoactive substance use & $-61 \%$ & $-54 \%$ & $-85 \%$ & \\
\hline
\end{tabular}

Notes: The table shows the percentage increase in risk of not having a specialist visit for nursing home residents (reference group: community-dwelling elderly without need of long-term care). Further covariates in the model: long-term care setting home care combined with the level of long term care need, gender, age, mortality, general practitioner visits, type of residential location and morbidity. Significant effects are printed bold, non-significant effects are printed italic

long-term care have less visits to medical specialists, especially those living in nursing homes $[9,10]$. Our results exceed previous findings showing that increasing levels of long-term care are associated with even lower specialist utilization. Although such kind of formal differentiation between different levels of long-term care need only exists in some countries so far [34-36], the implications of our findings may be cross-national: People who have limitations in the organization of daily activities may face barriers to medical care. The larger the limitations, the higher the risk of access barriers. One could argue that GPs might substitute the role of medical specialists among elderly in need of long-term care given the relatively high GP utilization of this group [9]. Yet, we controlled for GP utilization but did not find consistent or strong evidence for a relationship between GP visits and specialist visits (see Additional file 4): Having a GP visit either comes with a small decreased probability of not having a specialist visit or is unrelated to medical specialist utilization. 
Table 4 Home care recipients: LTC need level and the risk of having no medical specialist visit

\begin{tabular}{|c|c|c|c|c|c|}
\hline \multirow{2}{*}{$\begin{array}{l}\text { Medical } \\
\text { specialty }\end{array}$} & \multirow[b]{2}{*}{ Disease categories } & \multicolumn{4}{|c|}{ Long-term care setting: Home care } \\
\hline & & $\begin{array}{l}\text { Low } \\
\text { level }\end{array}$ & $\begin{array}{c}\text { Medium } \\
\text { level }\end{array}$ & $\begin{array}{l}\text { High } \\
\text { level }\end{array}$ & Visualiza \\
\hline \multirow{16}{*}{$\begin{array}{l}\text { Internal } \\
\text { medicine }\end{array}$} & Renal failure & $31 \%$ & $47 \%$ & $107 \%$ & \\
\hline & Respiratory disease & $28 \%$ & $63 \%$ & $42 \%$ & \\
\hline & Heart disease & $43 \%$ & $71 \%$ & $156 \%$ & \\
\hline & Mono- and polyneuropathy & $32 \%$ & $55 \%$ & $77 \%$ & \\
\hline & Nutrition-related disease & $36 \%$ & $76 \%$ & $99 \%$ & \\
\hline & Cerebrovaskular disease & $85 \%$ & $98 \%$ & $258 \%$ & \\
\hline & Coronary disease & $40 \%$ & $60 \%$ & $95 \%$ & \\
\hline & Intestinal disease & $40 \%$ & $90 \%$ & $184 \%$ & \\
\hline & Metabolic disorders & $48 \%$ & $68 \%$ & $145 \%$ & \\
\hline & Diabetes mellitus & $34 \%$ & $70 \%$ & $118 \%$ & \\
\hline & Thyroid disorders & $26 \%$ & $73 \%$ & $162 \%$ & \\
\hline & Parkinson's disease & $36 \%$ & $45 \%$ & $91 \%$ & \\
\hline & Arthropathy & $35 \%$ & $73 \%$ & $78 \%$ & \\
\hline & Hypertension & $40 \%$ & $67 \%$ & $111 \%$ & \\
\hline & Motor impairment $^{ \pm}$ & $-53 \%$ & $-50 \%$ & $-59 \%$ & \\
\hline & Palsy/paresis & $69 \%$ & $87 \%$ & $393 \%$ & \\
\hline \multirow{3}{*}{ Cardiology } & Heart disease & $47 \%$ & $84 \%$ & $394 \%$ & \\
\hline & Coronary disease & $52 \%$ & $93 \%$ & $459 \%$ & \\
\hline & Hypertension & $45 \%$ & $82 \%$ & $317 \%$ & \\
\hline Ophthalmology & Diseases of the eye & $136 \%$ & $330 \%$ & $913 \%$ & \\
\hline \multirow{5}{*}{ Orthopedics } & Osteopathy and hondropathy & $21 \%$ & $103 \%$ & $83 \%$ & \\
\hline & Arthropathy & $39 \%$ & $111 \%$ & $99 \%$ & \\
\hline & Injury & $52 \%$ & $127 \%$ & $141 \%$ & \\
\hline & Spinal disease & $29 \%$ & $131 \%$ & $71 \%$ & \\
\hline & Motor impairment ${ }^{\ddagger}$ & $-38 \%$ & $-63 \%$ & $-84 \%$ & \\
\hline \multirow{2}{*}{ Gynecology } & Diseases of the female genital tract & $33 \%$ & $60 \%$ & $103 \%$ & \\
\hline & Urinary tract disease & $64 \%$ & $164 \%$ & $98 \%$ & \\
\hline \multirow{2}{*}{ Urology } & Prostata disease & $58 \%$ & $80 \%$ & $62 \%$ & \\
\hline & Urinary tract disease & $120 \%$ & $165 \%$ & $160 \%$ & \\
\hline \multirow{2}{*}{ Surgery } & Injury & $19 \%$ & $10 \%$ & $49 \%$ & \\
\hline & Skin disease & $17 \%$ & $-12 \%$ & $-6 \%$ & \\
\hline \multirow{2}{*}{ Dermatology } & Skin disease & $43 \%$ & $84 \%$ & $203 \%$ & \\
\hline & Bedsore/decubitus & $55 \%$ & $103 \%$ & $655 \%$ & \\
\hline Otolaryngology & Disease of the ear & $39 \%$ & $76 \%$ & $232 \%$ & \\
\hline Nephrology & Renal failure & $-19 \%$ & $4 \%$ & $40 \%$ & \\
\hline Pneumology & Respiratory disease & $16 \%$ & $43 \%$ & $57 \%$ & \\
\hline \multirow{9}{*}{$\begin{array}{l}\text { Psychiatry / } \\
\text { Neurology }\end{array}$} & Parkinson's diseases & $-11 \%$ & $-4 \%$ & $56 \%$ & \\
\hline & Delusional/personality disorders & $-10 \%$ & $23 \%$ & $-40 \%$ & \\
\hline & Dementia-related disease & $-17 \%$ & $-25 \%$ & $-5 \%$ & \\
\hline & Palsy/paresis & $13 \%$ & $0 \%$ & $14 \%$ & \\
\hline & Depression & $1 \%$ & $1 \%$ & $9 \%$ & \\
\hline & Neurosis & $0 \%$ & $-8 \%$ & $30 \%$ & \\
\hline & Mono- and polyneuropathy & $12 \%$ & $18 \%$ & $72 \%$ & \\
\hline & Cerebrovascular disease & $7 \%$ & $-3 \%$ & $30 \%$ & \\
\hline & Disorders due to psychoactive substance use & $2 \%$ & $24 \%$ & $-12 \%$ & $\overline{1}$ \\
\hline
\end{tabular}

Notes: The table shows the percentage increase in risk of not having a specialist visit for nursing home residents (reference group: community-dwelling elderly without need of long-term care). Further covariates in the model: long-term care setting home care combined with the level of long term care need, gender, age, mortality, general practitioner visits, type of residential location and morbidity. Significant effects are printed bold, non-significant effects are printed italic

The gradient effects of the level of long-term care may be explained by objective or subjective access barriers. Especially elderly wheelchair users or homebound elderly face objective access barriers because in Germany, it is mostly GPs but not medical specialists who make (nursing) home visits. Subjective barriers to medical care also exist among elderly for instance feelings of shame in case of urinary incontinence [37]. Again other elderly perceive less need because of reduced health expectations. Contrary to younger people, older people perceive ageing as a natural, degenerative process not necessarily requiring a health care visit [38]. Also, they weigh the perceived value of medical care against the physical/ mental burden of seeking care [25]. Yet, there is little evidence on the health care seeking process of elderly people in need of long-term care, especially of those living in nursing homes.

Although we found clear gradient effects on the risk of having no medical specialist visit, we did not find suchlike effects on the intensity of received specialist care. 
On the one hand, the intensity of received specialist care may mostly depend on the severity of disease which is not reflected in our disease categories. On the other hand, claims data do not capture the actual number of visits per person. Multiple visits to the same medical specialist per quarter are documented only as one visit. Only if a patient visits different medical specialists per quarter then each visit is documented. Therefore, the results on the intensity of specialist care have to be interpreted with caution.

Further limitations of our data concern the generalizability and the explanatory power of the models. Despite the fact that the AOK health and long-term care insurance fund covers large parts of the population in Germany, samples from statutory health insurance funds are selective and may not be representative of the overall population [39]. Also, the analyses were based on elderly with a diagnosis in the investigated disease category. Such a diagnosis requires a previous practitioner visit. Consequently, elderly without a practitioner visit, despite a respective disease - were not included in the analyses.

Moreover, the explanatory power of the analyzed models was relatively low ranging from 0.023 to 0.211 (see Additional file 4). Although the McFadden pseudo $\mathrm{R}^{2}$ measure generally produces lower coefficients than the $R^{2}$ measure in linear regression analysis [40] our models do not include many of the factors that have been shown to explain health care utilization behavior [41-44]. For instance, health insurance claims data do not provide socioeconomic or demographic information which might have better explained differences in medical care utilization through differing health beliefs. Given the small range of covariates we did no systematic robustness test of our model.

\section{Conclusion}

Our results indicate lower medical care utilization among elderly with higher levels of long-term care. However, although the underlying mechanisms of the findings have not been investigated so far, the findings imply that nursing care personnel and family relatives may not always be able to recognize the need for medical care among older care-dependent people. Furthermore, the findings indicate, that some elderly in need for long-term care may perceive physical or emotional barriers to medical specialists. Depending on the underlying mechanism, these findings may imply that long-term care provider and family relatives should be better trained in the assessment of medical care needs. Furthermore, the organization of and access to medical care should be improved, e.g. by organizing more home visits by medical specialists, and by better cooperation between GPs and medical specialists.

\section{Supplementary information}

Supplementary information accompanies this paper at https://doi.org/10. 1186/s12939-020-1130-z.

Additional file 1. Descriptive statistics of covariates.

Additional file 2. Zero-inflated Poisson Regression analysis: Associations between LTC setting, level of LTC need, and medical specialist utilization.

Additional file 3. Zero-inflated Poisson Regression analysis - stability analyses: Associations between level of LTC need and medical specialist utilization, without long-term care setting.

Additional file 4. Association between GP visits and medical specialist visits.

\section{Abbreviations}

AOK: AOK health and long-term care insurance (Allgemeine Ortskrankenkasse); GP: General practitioner; ICD-10-GM: International Classification of Diseases, 10th Revision, German modification

\section{Acknowledgements}

The authors wish to thank Okka Kleimaker for their assistance in preparing, revising, and editing the manuscript.

\section{Authors' contributions}

All authors made substantial contributions to the concept and design of the study. CT and ASchw as members of the AOK Research Institute provided and analyzed the health insurance claims data. MS and JC reviewed and interpreted the data and wrote the article. ASchm, DG, FHGS, KW-O, SK and $\mathrm{HR}$ reviewed the article. All authors revised the current manuscript for submission. All authors read and approved the final article.

\section{Funding}

No funding was obtained for this study.

\section{Availability of data and materials}

The study is based on claims data that are located at the AOK Research Institute. These data are only available based upon a reasonable request and with permission of the AOK Research Institute.

Ethics approval and consent to participate

The study is based on claims data from the Allgemeine Ortskrankenkasse. Based on $\S 303$ e of the German Social Code Book V, the AOK Research Institute is commissioned and authorized to use these claims data for scientific purposes. Consequently, no particular ethical approval is needed.

Consent for publication

Not applicable.

\section{Competing interests}

The authors declare that they have no competing interests.

\section{Author details}

${ }^{1}$ University of Bremen, SOCIUM Research Center on Inequality and Social Policy, Mary-Somerville-Straße 5, 28359 Bremen, Germany. ${ }^{2}$ University of Bremen, Institute for Public Health and Nursing Research (IPP), Grazer Straße 4, 28359 Bremen, Germany. ${ }^{3}$ Research Institute of the Local Health Care Funds (WIdO), P.O. Box 1102 46, 10832 Berlin, Germany. ${ }^{4}$ University of Bremen, Competence Center for Clinical Trials (KKSB), Linzer Straße 4, 28359 Bremen, Germany. ${ }^{5}$ University of Bremen, High-Profile Area Health Sciences, Bremen, Germany.

Received: 16 July 2019 Accepted: 16 January 2020

Published online: 07 February 2020

\section{References}

1. Marengoni A, Angleman S, Melis R, Mangialasche F, Karp A, Garmen A, et al. Aging with multimorbidity: a systematic review of the literature. Ageing Res Rev. 2011;10(4):430-9. 
2. Collerton J, Jagger C, Yadegarfar ME, Davies K, Parker SG, Robinson L, et al. Deconstructing complex multimorbidity in the very old: findings from the Newcastle 85+ study. Biomed Res Int. 2016;2016:8745670.

3. Motel-Klingebiel A, Wurm S, Tesch-Römer C. Altern im Wandel: Befunde des Deutschen Alterssurveys (DEAS). Stuttgart: Kohlhammer Verlag; 2010.

4. Kleina T, Horn A, Suhr R, Schaeffer D. Zur Entwicklung der ärztlichen Versorgung in stationären Pflegeeinrichtungen-Ergebnisse einer empirischen Untersuchung. Das Gesundheitswesen. 2017;79(05):382-7.

5. Bussche H, Schön G, Kolonko T, Hansen H, Wegscheider K, Glaeske G, et al. Patterns of ambulatory medical care utilization in elderly patients with special reference to chronic diseases and multimorbidity-results from a claims data based observational study in Germany. BMC Geriatr. 2011;11(1):54

6. Glynn LG, Valderas JM, Healy P, Burke E, Newell J, Gillespie P, et al. The prevalence of multimorbidity in primary care and its effect on health care utilization and cost. Fam Pract. 2011;28(5):516-23.

7. Thibault $\mathrm{L}$, Kergoat $\mathrm{H}$. Eye care services for older institutionalised individuals affected by cognitive and visual deficits: a systematic review. Ophthalmic Physiol Opt. 2016;36(5):566-83.

8. Rothgang $H$, Müller R, Mundhenk R, Unger R. BARMER GEK Pflegereport 2014. Schwerpunkt: Zahnärztliche Versorgung Pflegebedürftiger. St. Augustin: Asgard-Verlag; 2014.

9. Schmiemann G, Herget-Rosenthal S, Hoffmann F. Ärztliche Versorgung von Pflegeheimbewohnern. Z Gerontol Geriat. 2015;49(8):727-33.

10. Balzer K, Butz S, Bentzel J, Boulkhemair D, Lühmann D. Beschreibung und Bewertung der fachärztlichen Versorgung von Pflegeheimbewohnern in Deutschland. Schriftenreihe Health Technology Assessment Bd 125; 2013.

11. Iliffe S, Davies SL, Gordon AL, Schneider J, Dening T, Bowman C, et al. Provision of NHS generalist and specialist services to care homes in England: review of surveys. Prim Health Care Res Dev. 2015;17(2):122-37.

12. Rothgang $H$, Borchert L, Müller R, Unger R. GEK Pflegereport 2008. Schwerpunktthema: Medizinische Versorgung in Pflegeheimen. St. Augustin: Asgard-Verlag; 2008

13. Cox CA, van Jaarsveld HJ, Houterman S, van der Stegen JC, Wasylewicz AT, Grouls RJ, et al. Psychotropic drug prescription and the risk of falls in nursing home residents. J Am Med Dir Assoc. 2016;17(12):1089-93.

14. Ouslander JG, Lamb G, Perloe M, Givens JH, Kluge L, Rutland T, et al. Potentially avoidable hospitalizations of nursing home residents: frequency, causes, and costs. J Am Geriatr Soc. 2010;58(4):627-35.

15. Lukas A, Mayer B, Onder G, Bernabei R, Denkinger MD. Schmerztherapie in deutschen Pflegeeinrichtungen im europäischen Vergleich. Ergebnisse der SHELTER-Studie Schmerz. 2015;29(4):411-21.

16. Johnell K. Inappropriate drug use in people with cognitive impairment and dementia: a systematic review. Curr Clin Pharmacol. 2015;10(3):178-84.

17. Morin L, Laroche M-L, Texier G, Johnell K. Prevalence of potentially inappropriate medication use in older adults living in nursing homes: a systematic review. J Am Med Dir Assoc. 2016;17(9):862.e1-9.

18. Colloca G, Tosato M, Vetrano DL, Topinkova E, Fialova D, Gindin J, et al. Inappropriate drugs in elderly patients with severe cognitive impairment: results from the shelter study. PLoS One. 2012;7(10):e46669.

19. Reeves D, Pye S, Ashcroft DM, Clegg A, Kontopantelis E, Blakeman T, et al. The challenge of ageing populations and patient frailty: can primary care adapt? BMJ. 2018;362:k3349.

20. Kojima G. Prevalence of frailty in nursing homes: a systematic review and meta-analysis. J Am Med Dir Assoc. 2015;16(11):940-5.

21. Björk S, Juthberg C, Lindkvist M, Wimo A, Sandman P-O, Winblad B, et al. Exploring the prevalence and variance of cognitive impairment, pain, neuropsychiatric symptoms and $A D L$ dependency among persons living in nursing homes; a cross-sectional study. BMC Geriatr. 2016;16(1):154.

22. Stock S, Ihle P, Simic D, Rupprecht C, Schubert I, Lappe V, et al. Prävalenz von Demenz bei Versicherten mit und ohne deutsche Staatsangehörigkeit. Bundesgesundheitsblatt-Gesundheitsforschung-Gesundheitsschutz. 2018; 61(4):404-11.

23. Prince $M$, Bryce $R$, Albanese E, Wimo A, Ribeiro W, Ferri CP. The global prevalence of dementia: A systematic review and metaanalysis. Alzheimers Dement. 2013;9(1):63-75.e2.

24. Hoffmann F, Kaduszkiewicz H, Glaeske G, van den Bussche H, Koller D. Prevalence of dementia in nursing home and community-dwelling older adults in Germany. Aging Clin Exp Res. 2014;26(5):555-9.

25. Niesten D, van Mourik K, van der Sanden W. The impact of frailty on oral care behavior of older people: a qualitative study. BMC Oral Health. 2013;13(1):61.
26. Wu B, Plassman BL, Crout RJ, Liang J. Cognitive function and oral health among community-dwelling older adults. J Gerontol Ser A Biol Med Sci. 2008;63(5):495-500.

27. Cooper C, Lodwick R, Walters K, Raine R, Manthorpe J, lliffe S, et al. Inequalities in receipt of mental and physical healthcare in people with dementia in the UK. Age Ageing. 2017;46(3):393-400.

28. Burton LC, German PS, Gruber-Baldini AL, Hebel JR, Zimmerman S, Magaziner J. Medical care for nursing home residents: differences by dementia status. Epidemiology of dementia in nursing homes research group. J Am Geriatr Soc. 2001;49(2):142-7.

29. Bussche $H$, Kaduszkiewicz $H$, Schäfer I, Koller D, Hansen $H$, Scherer $M$, et al. Overutilization of ambulatory medical care in the elderly German population?-An empirical study based on national insurance claims data and a review of foreign studies. BMC Health Serv Res. 2016;16(1):129.

30. Demographic change in the euro area: projections and consequences. European Central Bank Monthly Bulletin. 2006, 49-64.

31. Balzer K, Butz S, Bentzel J, Boulkhemair D, Lühmann D. Beschreibung und Bewertung der fachärztlichen Versorgung von Pflegeheimbewohnern in Deutschland. Schriftenreihe Health Technology Assessment Bd 125. Köln: DIMDI; 2013.

32. Bähler C, Huber CA, Brüngger B, Reich O. Multimorbidity, health care utilization and costs in an elderly community-dwelling population: a claims data based observational study. BMC Health Serv Res. 2015;15(1):23.

33. Beaujean AA, Morgan GB. Tutorial on using regression models with count outcomes using R. Pract Assess Res Eval. 2016;21:2.

34. Tenand $\mathrm{M}, \mathrm{Bakx} \mathrm{P}$, van Doorslaer E. Long-term care use in the Netherlands: equal care for equal needs? An assessment using adminstrative data. mimeo; 2018.

35. Iwagami M, Tamiya N. The long-term care insurance system in Japan: past, present, and future. JMA J. 2019;2(1):67-9.

36. Jeon B, Kwon S. Health and long-term care systems for older people in the republic of Korea: policy challenges and lessons. Health Syst Reform. 2017;3(3):214-23.

37. Vethanayagam N, Orrell A, Dahlberg L, McKee KJ, Orme S, Parker SG, et al. Understanding help-seeking in older people with urinary incontinence: an interview study. Health Soc Care Community. 2017;25(3):1061-9.

38. Horrocks S, Somerset M, Stoddart H, Peters TJ. What prevents older people from seeking treatment for urinary incontinence? A qualitative exploration of barriers to the use of community continence services. Fam Pract. 2004;21(6):689-96.

39. Hoffmann F, Icks A. Structural differences between health insurance funds and their impact on health services research: results from the Bertelsmann health-care monitor. Gesundheitswesen. 2012;74(5):291-7.

40. Scott LJ. Regression models for categorical and limited dependent variables. In: Advanced quantitative techniques in the social sciences; 1997. p. 7.

41. Bremer D, Inhestern L, von dem Knesebeck O. Social relationships and physician utilization among older adults - a systematic review. PLoS One. 2017;12(9):e0185672

42. Hoebel J, Rattay P, Prütz F, Rommel A, Lampert T. Socioeconomic status and use of outpatient medical care: the case of Germany. PLoS One. 2016;11(5):e0155982.

43. Hoebel J, Rommel A, Schröder LS, Fuchs J, Nowossadeck E, Lampert T. Socioeconomic Inequalities in Health and Perceived Unmet Needs for Healthcare among the Elderly in Germany. Int J Environ Res Public Health. 2017;14(10):1127.

44. Terraneo M. Inequities in health care utilization by people aged 50+: evidence from 12 European countries. Soc Sci Med. 2015;126:154-63.

\section{Publisher's Note}

Springer Nature remains neutral with regard to jurisdictional claims in published maps and institutional affiliations.

Ready to submit your research? Choose BMC and benefit from:

- fast, convenient online submission

- thorough peer review by experienced researchers in your field

- rapid publication on acceptance

- support for research data, including large and complex data types

- gold Open Access which fosters wider collaboration and increased citations

- maximum visibility for your research: over $100 \mathrm{M}$ website views per year

At $\mathrm{BMC}$, research is always in progress.

Learn more biomedcentral.com/submissions 